\title{
Back to (new) normality-A CODRAL/AIRO-L survey on cancer radiotherapy in Lombardy during Italian COVID-19 phase 2
}

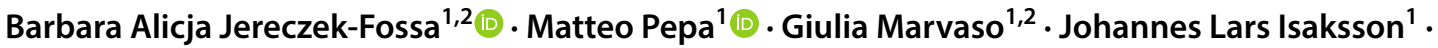 \\ Carlo Pietro Soatti ${ }^{3}$. Luigi Franco Cazzaniga ${ }^{4}$. Giovanni Battista Ivaldi ${ }^{5} \cdot$ Marcello Amadori $^{6}$. Paolo Antognoni ${ }^{7}$. \\ Stefano Arcangeli ${ }^{8}$. Alberto Buffoli ${ }^{9} \cdot$ Giancarlo Beltramo $^{10} \cdot$ Mario Bignardi $^{11}$. Stefano Bracelli ${ }^{12}$. \\ Lorenza Bruschieri ${ }^{13}$. Simona Castiglioni ${ }^{14}$. Gianpiero Catalano ${ }^{15}$. Nadia Di Muzio ${ }^{16}$ (1) . Carlo Fallai ${ }^{17}$. \\ Laura Fariselli ${ }^{18}$. Andrea Riccardo Filippi ${ }^{19}$. Alberto Gramaglia ${ }^{20}$. Corrado Italia ${ }^{21}$. Fabrizio Lombardi ${ }^{22}$. \\ Stefano Maria Magrini ${ }^{23}$. Simonetta $\mathrm{Nava}^{24} \cdot$ Ester Orlandi $^{25} \cdot$ Nadia Pasinetti $^{26}$ - Elena Lara Sbicego ${ }^{27}$. \\ Luciano Scandolaro ${ }^{28} \cdot$ Marta Scorsetti $^{29,30} \cdot$ Francesco Stiglich $^{31} \cdot$ Roberto Tortini $^{32} \cdot$ Riccardo Valdagni $^{2,17}$. \\ Vittorio Vavassori ${ }^{33}$. Sandro Tonoli ${ }^{34}$. Mauro Filippo Palazzi ${ }^{35}$. on behalf of the CODRAL (Board of Directors of \\ Radiation Oncology Departments in Lombardy) network and of AIRO-L (Italian Association of Radiotherapy and \\ Clinical Oncology - Lombardy)
}

Received: 27 August 2020 / Accepted: 23 October 2020 / Published online: 4 November 2020

(c) Springer Science+Business Media, LLC, part of Springer Nature 2020

\begin{abstract}
Background Italy experienced one of the world's severest COVID-19 outbreak, with Lombardy being the most afflicted region. However, the imposed safety measures allowed to flatten the epidemic curve and hence to ease the restrictions and inaugurate, on the 4th of May 2020, the Italian phase (P) 2 of the pandemic. The present survey study, endorsed by CODRAL and AIRO-L, aimed to assess how radiotherapy (RT) departments in Lombardy have dealt with the recovery.

Materials and methods A questionnaire dealing with the management of pandemic was developed online and sent to all CODRAL Directors on the 10th of June 2020. Answers were collected in full anonymity one week after.

Results All the 33 contacted RT facilities (100\%) responded to the survey. Despite the scale of the pandemic, during P1 14 $(42.4 \%)$ centres managed to safely continue the activity ( $\leq 10 \%$ reduction). During P2, 10 (30.3\%) centres fully recovered and $14(42.4 \%)$ reported an increase. Nonetheless, $6(18.2 \%)$ declared no changes and, interestingly, $3(9.1 \%)$ reduced activities. Overall, 21 centres (63.6\%) reported suspected or positive cases within healthcare workforce since the beginning of the pandemic. Staff units were quarantined in $19(57.6 \%)$ and 6 (18.2\%) centres throughout P1 and P2, respectively. In the two phases, about two thirds centres registered positive or suspected cases amongst patients.

Conclusion The study revealed a particular attention to anti-contagion measures and a return to normal or even higher clinical workload in most RT centres in Lombardy, necessary to carry out current and previously deferred treatments.
\end{abstract}

Keywords COVID-19 $\cdot$ Survey $\cdot$ Cancer radiotherapy $\cdot$ Lombardy $\cdot$ Northern Italy

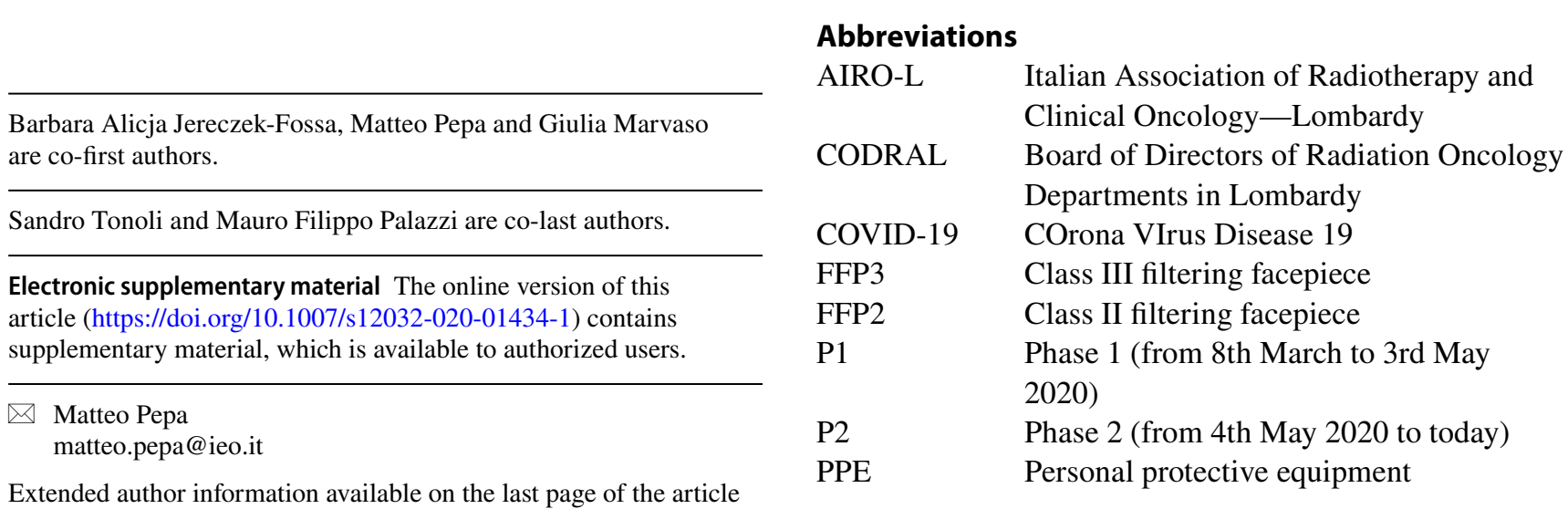


RT Radiotherapy

SARS-CoV-2 Severe Acute Respiratory SyndromeCorona Virus-2

\section{Introduction}

Since the 20th February 2020, Lombardy has represented for a long time the Italian and European epicentre of the novel COrona VIrus Disease 19 (COVID-19) pandemic. However, whilst the infection is still dramatically expanding around the world, all the adopted countermeasures in Italy to flatten the epidemic curve efficiently guided the Country towards a significantly better epidemiological situation. Therefore, at the end of April, when the pandemic passed its peak and the daily confirmed cases and deaths started to substantially decrease, the Government decided to gradually ease the restrictions and to inaugurate the so-called Italian phase 2 (P2), which replaced, on the 4th May 2020, the lockdown phase $1(\mathrm{P} 1)$ previously in force.

During P1, a major effect was observed on healthcare facilities due to their unpreparedness for such an unprecedented event. Healthcare resources and efforts were inevitably diverted and concentrated to hospitalized COVID-19 patients, so clinical and outpatient activities of all other medical specialties strongly decreased. However, as far as cancer radiotherapy (RT) was concerned, departments in Italy and in Lombardy experienced only a little reduction, if compared to the entity of the emergency [1, 2]. In fact, even though cancer patients represent one of the most vulnerable groups towards the Severe Acute Respiratory Syndrome-Corona Virus-2 (SARS-CoV-2) infection [3-6], it is estimated that as many as $50 \%$ of them need RT cures $[7,8]$. Therefore, since the beginning of the pandemic, RT practitioners in Lombardy immediately rethought their clinical practice to cope with limited resources and to deliver undelayable cures whilst keeping the infection rate level extremely low amongst patients and healthcare workforce. The national guidelines provided by the Italian Association of Radiotherapy and Clinical Oncology (AIRO) [9] contributed to guide the Italian radiation oncologists in pursuing an optimal balance between risk of cancer progression and risk of infection [1].

The transition towards P2 brought important modifications in the emergency setting of the RT Departments in Lombardy, which have started to gradually resume normal activities. Previous surveys have already investigated the effect of pandemic on RT centres in USA [10], Europe [11], Italy [1] and Lombardy [2]. The present study represents a continuation of the one conducted in Lombardy during P1 [1] and aims at investigating, by means of a questionnaire, how Lombardian RT facilities have faced up the recovery during P2.

\section{Materials and methods}

The study is based on a survey addressed to the 34 Directors of RT facilities of Lombardy associated to the Board of Directors of Radiation Oncology Departments in Lombardy_Italian Association of Radiotherapy and Clinical Oncology-Lombardy (CODRAL-AIRO-L) network, that is to 33 expected responders, as two Directors were coheads in one hospital and were supposed to compile the survey jointly. The questionnaire was readapted from the P1 counterpart, with some queries reformulated according to the current epidemiological and legislative scenario. Two extra sections dealing with cases amongst staff and with the results of the screening endorsed by Lombardy region were included. The final version was anonymously sent, via Google Forms, to all CODRAL-AIRO-L Directors on the 10th of June 2020 and answers were collected after one week. The questionnaire aimed at assessing to what extent the clinical and outpatient activities had been restored and at investigating statistics of suspected or positive patients and staff as well as the anti-contagion measures put in place during P2. By responding to the survey, all participants also agreed to the publication of the related results.

\section{Results}

At the due date, all 33 contacted RT facilities (100\%) responded to the survey. All responses were collected in full anonymity. Out of the surveyed centres, the median range of number of treated patients was 500-1000 (see Supplementary Materials-Text of Survey, part 1, question 2) and 28 hospitals hosting the RT facilities (85\%) had become COVID-19 centres in response to the pandemic in P1. Out of 9 centres with an inpatient ward, 2 were converted in COVID-19 ward during P1, both of these centres reverted partially or completely to normal in $\mathrm{P} 2$.

Twenty-five centres (76\%) had to reorganize their clinical activity during $\mathrm{P} 1-22$ centres reported postponing treatment for certain pathologies (especially breast and prostate) on a case-by-case basis, and 21 centres reported favouring short-term treatments (dose hypofractionation). Nine centres (27\%) reported no significant change in clinical activity transitioning from P1 to P2. Out of the remaining $24,21(64 \%)$ revaluated the previously postponed treatments, and one centre returned to normal activity. Thirty-two centres (97\%) cancelled on-site routine follow-up visits during P1, 20 of which (61\%) opting for telematic consultations instead. In P2, ordinary check-ups remained cancelled in 25 centres $(76 \%)$ whilst maintaining 
Table 1 Clinical and outpatient activities during P1 and P2

\begin{tabular}{|c|c|c|c|c|c|}
\hline & & \multicolumn{2}{|l|}{ P1 } & \multicolumn{2}{|l|}{$\mathrm{P} 2$} \\
\hline & & Action & $\mathrm{N}(\%)$ & Action & $\mathrm{N}(\%)$ \\
\hline \multirow[t]{10}{*}{ Therapeutic } & Overall changes & No changes wrt pre-COVID-19 era & $8(24.2)$ & No changes wrt P1 & $9(27.3)$ \\
\hline & \multirow[t]{2}{*}{ All treatments } & \multirow[t]{2}{*}{$\begin{array}{l}\text { Delaying treatments for some } \\
\text { pathologies }\end{array}$} & \multirow[t]{2}{*}{$22(66.7)$} & $\begin{array}{l}\text { All delayed treatments are still in } \\
\text { stand-by }\end{array}$ & $0(0)$ \\
\hline & & & & $\begin{array}{l}\text { Delayed treatments are selec- } \\
\text { tively reactivated }\end{array}$ & $21(63.6)$ \\
\hline & \multirow[t]{2}{*}{ Palliative cures } & \multirow[t]{2}{*}{$\begin{array}{l}\text { Favouring home cures in palliative } \\
\text { setting }\end{array}$} & \multirow[t]{2}{*}{$8(24.2)$} & $\begin{array}{l}\text { Still favouring home cures in pal- } \\
\text { liative setting }\end{array}$ & $0(0)$ \\
\hline & & & & $\begin{array}{l}\text { Reactivating palliative cures as in } \\
\text { pre-COVID-19 era }\end{array}$ & $10(30.3)$ \\
\hline & Undelayable treatments & $\begin{array}{l}\text { Performing only non-deferrable } \\
\text { treatments }\end{array}$ & $9(27.3)$ & $\begin{array}{l}\text { Still performing only non-deferra- } \\
\text { ble treatments }\end{array}$ & $0(0)$ \\
\hline & \multirow[t]{2}{*}{ Hypofractionation } & \multirow[t]{2}{*}{ Favouring hypofractionation } & \multirow[t]{2}{*}{$21(63.6)$} & $\begin{array}{l}\text { Favouring hypofractionation also } \\
\text { when strength of recommenda- } \\
\text { tion is low }\end{array}$ & $7(21.2)$ \\
\hline & & & & $\begin{array}{l}\text { Choosing hypofractionation only } \\
\text { when strength of recommenda- } \\
\text { tion is high }\end{array}$ & $10(30.3)$ \\
\hline & \multirow[t]{2}{*}{ Management of fragile patients } & \multirow[t]{2}{*}{$\begin{array}{l}\text { Suspending treatments of fragile } \\
\text { patients }\end{array}$} & \multirow[t]{2}{*}{$3(9.1)$} & $\begin{array}{l}\text { Treatments of fragile patients are } \\
\text { still suspended }\end{array}$ & $0(0)$ \\
\hline & & & & $\begin{array}{l}\text { Treatments of fragile patients have } \\
\text { been reactivated }\end{array}$ & $8(24.2)$ \\
\hline \multirow[t]{6}{*}{ Outpatient } & Overall changes & No changes wrt pre-COVID-19 era & $1(3)$ & $\begin{array}{l}\text { No changes wrt P1, as no changes } \\
\text { wrt pre-COVID-19 era were } \\
\text { made }\end{array}$ & $2(6.1)$ \\
\hline & \multirow[t]{2}{*}{ Follow-up consultations } & \multirow[t]{2}{*}{$\begin{array}{l}\text { Routine follow-up consultations } \\
\text { have been cancelled }\end{array}$} & \multirow[t]{2}{*}{$32(97)$} & $\begin{array}{l}\text { Only high-priority follow-up con- } \\
\text { sultations have been reactivated }\end{array}$ & $7(21.2)$ \\
\hline & & & & $\begin{array}{l}\text { All follow-up consultations have } \\
\text { been reactivated }\end{array}$ & $25(75.8)$ \\
\hline & \multirow[t]{2}{*}{ First visits } & \multirow[t]{2}{*}{ First visits have been cancelled } & \multirow[t]{2}{*}{$1(3)$} & First visits are still suspended & $0(0)$ \\
\hline & & & & First visits were restored & $9(27.3)$ \\
\hline & Telehealth & $\begin{array}{l}\text { Telematic visits replaced those } \\
\text { cancelled }\end{array}$ & $20(60.6)$ & $\begin{array}{l}\text { Telematic visits replaced those } \\
\text { cancelled }\end{array}$ & $9(27.3)$ \\
\hline
\end{tabular}

Actions undertaken by more than half responders have been highlighted in bold

COVID-19 Coronavirus disease $19, N$ number of centres, $P 1 / 2$ Italian phase $1 / 2$, wrt with respect to

those due to high risk of recurrence (acute toxicity from RT, etc.) (Table 1). Additionally, more than 3 out of 4 centres reactivated follow-up consultations, which were cancelled almost everywhere during P1 and replaced by telematic visits in most cases (Table 1). However, the danger level is still high, as more than $70 \%$ centres would opt for always interrupting the treatment of positive patients and for suspending the cures for a sufficient timeframe for those with a suspected infection (Table 2).

During P1, 17 centres (52\%) experienced a 10-30\% reduction of clinical activity (Figure S1a). The two centres that experienced the highest decrease (30-50\% and $>70 \%$ increase, respectively) are both small centres, treating less than 500 patients per year. Six centres (18\%) reported no change in clinical activity from P1 to P2, whereas 14 (42\%) reported an increase, and 10 (30\%) reopened completely.
The remaining three centres (9\%) even reported a decrease in activity (Figure $\mathrm{S} 1 \mathrm{~b}$ ).

In $\mathrm{P} 2$, triage procedures remain active in all centres, and are in most cases (29 centres, $88 \%$ ) performed at the entrance of the hospital. Triage procedures before accessing the RT Department are performed by all staff members, with a marked prevalence of nurses (19 centres, $79 \%$ ). To limit contamination, the most of P1 measures are continued in $\mathrm{P} 2$, and patients in all centres are provided with surgical masks. All but two centres (31) employ mandatory personal distancing, 31 centres regularly disinfect the premises, 27 centres limit access only to patients, and 24 centres enforce mandatory hand sanitizing. Figure S2 summarizes the most widely adopted infection prevention and control strategies amongst patients. 
Table 2 Management of positive or suspect patients during radiotherapy (RT) treatment

\begin{tabular}{|c|c|c|c|c|}
\hline \multirow[t]{2}{*}{ General strategy } & \multicolumn{2}{|l|}{ Positive ( 22 centres) } & \multicolumn{2}{|l|}{ Suspect ( 23 centres) } \\
\hline & Action & $\mathrm{N}(\% *)$ & Action & $\mathrm{N}(\% * *)$ \\
\hline \multirow[t]{2}{*}{ RT interruption } & Always RT interruption & $16(72.7)$ & RT suspended for two weeks & $8(34.8)$ \\
\hline & & & A swab was required & $9(39.2)$ \\
\hline \multirow[t]{3}{*}{ RT continuation } & $\begin{array}{l}\text { RT continued if asymptomatic, independently from the } \\
\text { anatomical site of tumour }\end{array}$ & $2(9.1)$ & RT continued with special precautions & $3(13.0)$ \\
\hline & $\begin{array}{l}\text { RT continued if asymptomatic, for all anatomical sites of } \\
\text { tumour except thoracic malignancies }\end{array}$ & $2(9.1)$ & RT continued without extra precautions $* * *$ & $3(13.0)$ \\
\hline & RT continued only in selected cases & $2(9.1)$ & & \\
\hline
\end{tabular}

*\% is computed considering the number of centres reporting positive cases (22)

**\% is computed considering the number of centres reporting suspect cases (23)

*** Only for in-patients

Twenty-two centres (67\%) reported having COVID19 positive patients in treatment. Out of these, the most common approach was termination of treatment (16 centres). Eleven centres (33\%) reported no COVID-19 positive patients at all. Ten centres (30\%) did not report any patients with documented contact with infected people.
The most common approaches in centres that had such cases were requesting a swab test ( 9 centres), postponing treatment for two weeks ( 8 centres), and continuation of treatment ( 6 centres). Out of the six centres reporting 10 or more cases before treatment, two treat less than

(a)

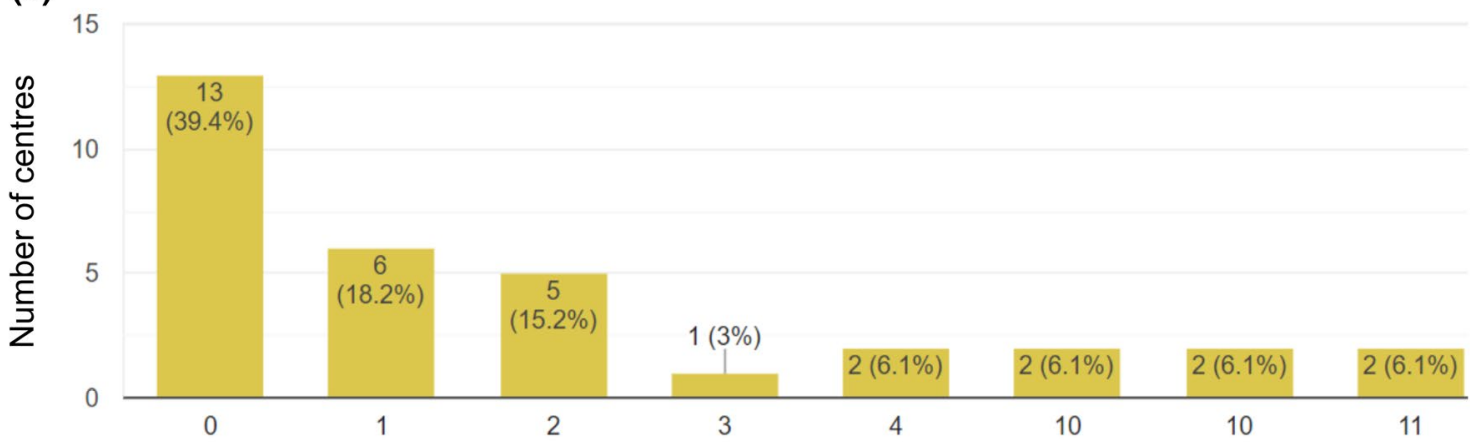

Number of reported positive patients (before RT start)

(b)

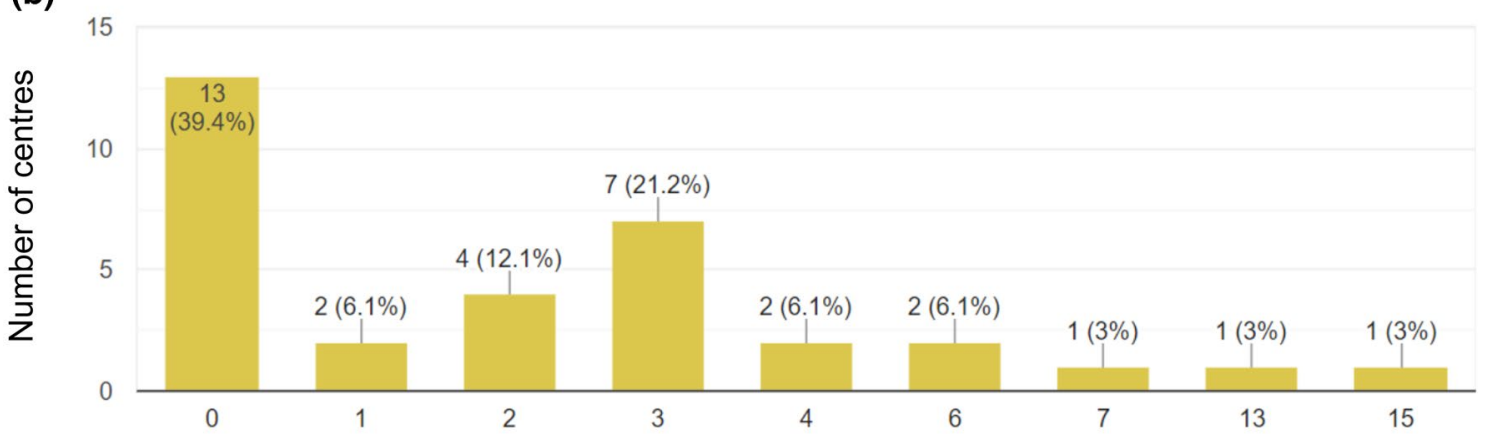

Number of reported positive patients (during RT)

Fig. 1 Distribution of positive patients before the beginning of radiotherapy (RT) (a) and during treatment (b) 
500 patients per year and only one treats more than 3000 patients per year (Fig. 1, Table 2).

To limit the spread of the virus from staff to patients, the personnel of all RT centres in Lombardy were equipped with some form of personal protective equipment (PPE). More

(a) Radiation Oncologists

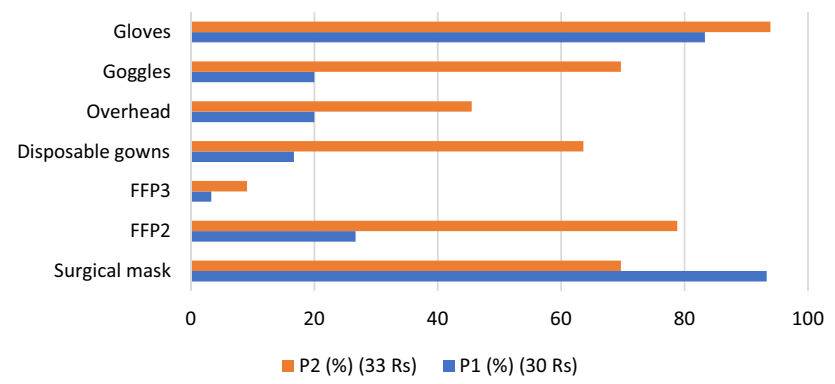

(b) Nurses and Radiotherapy Technicians

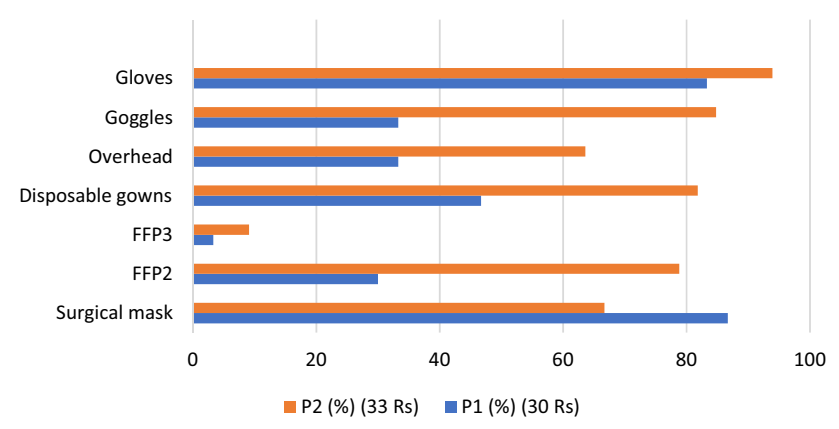

Fig. 2 Provision of personal protective equipment (PPE) during P1 and $\mathrm{P} 2$ to radiation oncologists (a) and nurses and radiotherapy technicians (b). FFP2/3 Class II/III filtering facepiece, P1/2 Italian phase $1 / 2, P P E$ personal protective equipment, $R$ responder. NB. P1 results refer to the previously published work (Jereczek-Fossa BA, Palazzi $M F$, Soatti CP, et al. COVID-19 Outbreak and Cancer Radiotherapy Disruption in Lombardy, Northern Italy. Clin Oncol (R Coll Radiol). 2020;32(7):e160-e161. https://doi.org/10.1016/j.clon.2020.04.007). $P 2$ results, instead, were collected in the context of the current investigation than one third of centres do not apply any specific criterion concerning the distribution of PPE to personnel in direct contact with patients. Other centres differentiate according to the treated pathology (e.g. more sophisticated devices for contacts with head and neck patients) (17 centres, 52\%) or on the basis of the suspected (11 centres, 33\%) or confirmed (9 centres, 27\%) infection status of the treated patient.

Appropriate PPE are widely available in P2. For instance, class II (FFP2) and class III (FFP3) filtering facepieces were made available to physicians, nurses, and RT technicians in 29 centres (88\%) during P2 (Fig. 2). Four centres (12\%) reallowed all meetings between healthcare professionals as normal during P2, whereas two centres still disallowed them altogether. The majority ( 24 centres, $73 \%$ ) resumed meetings with restrictions such as personal distancing and attendance limitations. More than $60 \%$ of centres (22) still adopt workfrom-home solutions, especially for personnel not directly involved in the clinical routine. Similarly to P1, the physical and technical controls on linear accelerators are guaranteed in almost all centres $(31,93.9 \%)$.

A large decrease in quarantined personnel were reported in P2 (total: 9, $\max : 2$ ) compared to P1 (total: 80, $\max : 18$ ). Overall, 50 confirmed COVID-19 cases amongst professionals, out of the 554 overall working in the RT centres (9.0\%) were reported (Table 3). A single COVID-19 related fatality was reported within staff members. Fourteen centres (42\%) reported displacement of staff as a crisis management operation. Of these cases, eleven reported displacement to a COVID-19 ward, two to triage activity, two to other radiotherapy departments in difficulty due to the epidemic, and two to other crisis units. In roughly $90 \%$ of centres (30), the RT staff has undergone the screening provided by the Lombardy Region for the detection of anti-COVID-19 antibodies. Cases of positive serology and negative swabs were most frequent amongst RT technicians (14/24 centres, 25 total cases), closely followed by clinicians (11/27 centres, 15 total cases) (Table 4).
Table 3 COVID-19 cases amongst Lombardy RT staff

\begin{tabular}{|c|c|c|c|c|c|c|c|c|c|c|c|c|}
\hline & \multicolumn{2}{|c|}{ Rad Oncol } & \multicolumn{2}{|c|}{ RTT } & \multicolumn{2}{|c|}{ Nurses } & \multicolumn{2}{|c|}{ Admin } & \multicolumn{2}{|c|}{ Physicists } & \multicolumn{2}{|l|}{ All } \\
\hline & $N$ & $\%$ & $N$ & $\%$ & $N$ & $\%$ & $N$ & $\%$ & $N$ & $\%$ & $N$ & $\%$ \\
\hline Total & 170 & 100.0 & 193 & 100.0 & 80 & 100.0 & 35 & 100.0 & 76 & 100.0 & 554 & 100.0 \\
\hline Suspect & 26 & 15.3 & 31 & 16.1 & 17 & 21.3 & 3 & 8.6 & 3 & 3.9 & 80 & 14.4 \\
\hline Tested & 24 & 14.1 & 19 & 9.8 & 14 & 17.5 & 1 & 2.9 & 2 & 1.3 & 59 & 10.6 \\
\hline Positive & 16 & 9.4 & 18 & 9.3 & 13 & 16.3 & 1 & 2.9 & 2 & 2.6 & 50 & 9.0 \\
\hline
\end{tabular}

The sum of all suspected cases (suspect), tested cases with swab (tested), positive cases after swab (positive), out of the total number of units of staff (total), are reported, in absolute value $(\mathrm{N})$ and in percentage $(\%)$, for each working category namely radiation oncologists including specialists and residents ( $\mathrm{rad}$ oncol), radiotherapy technicians (RTT), nurses, administrative staff (admin) and medical physicists (physicists) and all of them together (all). Data refer only to the 21 centres out of the 33 interviewed which reported positive cases amongst healthcare workforces. Data were not available for 2 units of personnel in 4 centres and in 4 units of personnel in 1 centre 
Table 4 Results of the screening endorsed by Lombardy Region

\begin{tabular}{|c|c|c|c|c|c|c|c|c|c|c|c|c|c|c|c|c|c|}
\hline & \multicolumn{3}{|c|}{ Rad Oncol } & \multicolumn{3}{|c|}{ RTT } & \multicolumn{3}{|c|}{ Nurses } & \multicolumn{3}{|c|}{ Admin } & \multicolumn{3}{|c|}{ Physicists } & \multicolumn{2}{|l|}{ All } \\
\hline & $N$ & $\%$ & Mean & $N$ & $\%$ & Mean & $N$ & $\%$ & Mean & $N$ & $\%$ & Mean & $N$ & $\%$ & Mean & $N$ & $\%$ \\
\hline No centres & 30 & 90.9 & - & 28 & 84.8 & - & 28 & 84.8 & - & 19 & 57.6 & - & 28 & 84.8 & - & - & - \\
\hline Total & 238 & 100.0 & 8 & 299 & 100.0 & 11 & 117 & 100.0 & 4 & 54 & 100.0 & 3 & 116 & 100.0 & 4 & 824 & 100.0 \\
\hline SE- & 214 & 89.9 & 7 & 225 & 75.3 & 9 & 83 & 70.9 & 3 & 36 & 66.7 & 2 & 95 & 81.9 & 4 & 653 & 79.2 \\
\hline $\mathrm{SE}+/ \mathrm{SW}-$ & 15 & 6.3 & 1 & 25 & 8.4 & 1 & 3 & 2.6 & 0 & 2 & 3.7 & 0 & 6 & 5.2 & 0 & 51 & 6.2 \\
\hline $\mathrm{SE}+/ \mathrm{SW}+$ & 7 & 2.9 & 0 & 9 & 3.0 & 0 & 13 & 11.1 & 1 & 0 & 0.0 & 0 & 6 & 5.2 & 0 & 35 & 4.2 \\
\hline Unknown & 13 & 5.5 & 1 & 35 & 11.7 & 3 & 9 & 7.7 & 1 & 10 & 18.5 & 1 & 13 & 11.2 & 1 & 80 & 9.7 \\
\hline
\end{tabular}

Data refer only to the number of responders who have adhered to the screening endorsed by the Lombardy Region for the specific working category $\left(N^{\circ}\right.$ centres), in absolute values $(N)$ and in percentage $(\%)$ with respect to the 33 interviewed centres. The sum of cases of negative serology $(S E-)$, positive serology in conjunction with negative swab $(S E+/ S W-)$, positive serology in conjunction with positive swab $(S E+/ S W+)$ and cases for which data were not available (unknown), out of the total number of units of staff (total), are reported, in absolute value $(N)$ in percentage with respect to total (\%) and averaged per $n^{\circ}$ centre (Mean), for each working category—namely radiation oncologists including specialists and residents ( $\mathrm{rad}$ oncol), radiotherapy technicians (RTT), nurses, administrative staff (admin) and medical physicists (physicists) and all of them together (all). Missing values for total were imputed as the sum of $S E-, S E+/ S W-, S E+/ S W+$ and unknown

\section{Discussion}

Despite the official end of P1, in compliance with the epidemiological scenario, which remains uncertain in most countries in the world, the survey has shown that several measures adopted during P1 in RT departments of Lombardy remained unchanged during P2. This is in accordance with the Italian legislative framework in force, which has established the extension of the state of emergency until January 31st 2021 [12].

All policies concerning the management of the people accessing the RT facilities were maintained virtually unmodified in most centres. Accordingly, no accompanying persons can access the RT facility unless in exceptional cases and patients are only allowed to enter after exhaustive triage procedures. Additionally, admitted patients must wear a surgical mask and keep interpersonal distancing.

The survey shows that the clinical and outpatient activities have been gradually recovering to normality. Most facilities $(24,72 \%)$ reported an increase in clinical workload in P2 with respect to P1 (Figure S1b). Almost all the centres which had previously delayed treatments for some pathologies, have been proceeding with a selective reactivation in P2. This was also made possible by the larger availability of guidance documents concerning the best management of RT patients in the COVID-19 era. Most recent ones concern lung malignancies [13-17], head and neck tumours [18-20], prostate cancer [21], breast cancer [22, 23] and other cancer districts [24-29]. Hypofractionation in unconventional settings, a largely adopted strategy during P1 to reduce treatment duration without compromising the oncological outcome [30-34], has been abandoned during P2 by 10 radiation oncologists $(30.3 \%)$, which declared to opt for it only when strength of recommendation is high (Table 1).
During P1, the centres suffered from a shortage of PPE as, for instance, in less than $30 \%$ facilities FFP2s were available to radiation oncologists, nurses and technicians. Nevertheless, all the other adopted measures allowed to compensate for this defect and were proven to be successful to contain the spread of the infection amongst professionals, as, overall, less than 1 out of 10 persons working in RT Departments of Lombardy was tested positive to SARS-CoV-2 (Table 3). However, this proportion is expected to increase to some extent if one considers that approximately one third centres reported cases of positive serology and negative swab amongst RT technicians and clinicians, indicating a possible previous infection. To note that, given the individual nature of serology data not all the responders may have access to them (Table 4).

The gradual seeking for a new normality that should characterize $\mathrm{P} 2$ has been accompanied by an even higher attention to healthcare staff. First and foremost, more sophisticated protective devices have replaced the inadequate PPE previously available (Fig. 2) and facilitated a large decrease in quarantined persons during P2. Secondly, but not less important, more than $90 \%$ centres have adhered to the screening procedures endorsed by the Lombardy region, which allows to periodically monitor the healthcare professionals, to be able to promptly detect positive cases and adopt the necessary countermeasures. In addition, in more than $60 \%$ facilities remote working solutions remain active, meaning that they still represent a valid option for carrying out office-based activities whilst reducing contacts. This new realty based on the improved health care staff-, patient- and ambient protection together with a higher general public awareness will be a prerequisite for mitigation of COVID-19 impact in the near future. 


\section{Conclusions}

The P1 survey showed how RT departments in Lombardy had rapidly coped with the COVID-19 disruption, by efficiently balancing the risk of infection and the oncological benefit of RT cures on a case-by-case basis. The present P2 study demonstrated a return to normal or even higher clinical activity in most Lombardian RT centres, as all the treatments delayed/suspended during $\mathrm{P} 1$ have been progressively added to the normal workload. The improved staff, patients and ambient anti-contagion measures are expected to be of paramount importance to contain the negative impact of a possible second wave of pandemic. Even though Italy and Lombardy are experiencing a better situation, the epidemiological scenario all over the world remains critical. As Lombardy was one of the first western regions to face this pandemic, and consequently one of the first to start the recovery phase, the present investigation could provide guidance for other RT facilities still in the middle of the pandemic.

Acknowledgements JLI is a Ph.D. student within the European School of Molecular Medicine (SEMM), Milan, Italy. The authors wish to thank Mattia Zaffaroni MSc for his contribute to this work. IEO, the Institution of Authors BAJF, MP, GM and JLI, was also partially supported by the Italian Ministry of Health with Ricerca Corrente and 5 $\times 1000$ funds.

Funding None.

\section{Compliance with ethical standards}

Conflicts of interest The authors declare that they have no conflict of interest.

Consent to participate Participation to the survey was voluntary. Participants could withdraw at any time.

Consent for publication All participants authorized the publication of the results of the survey.

\section{References}

1. Jereczek-Fossa BA, Pepa M, Marvaso G, et al. COVID-19 outbreak and cancer radiotherapy disruption in Italy: Survey endorsed by the Italian Association of Radiotherapy and Clinical Oncology (AIRO). Radiother Oncol. 2020;149:89-93. https://doi. org/10.1016/j.radonc.2020.04.061.

2. Jereczek-Fossa BA, Palazzi MF, Soatti CP, et al. COVID-19 outbreak and cancer radiotherapy disruption in Lombardy, Northern Italy. Clin Oncol (R Coll Radiol). 2020;32(7):e160-1. https://doi. org/10.1016/j.clon.2020.04.007.

3. Liang W, Guan W, Chen R, et al. Cancer patients in SARSCoV-2 infection: a nationwide analysis in China. Lancet Oncol. 2020;21(3):335-7. https://doi.org/10.1016/S1470-2045(20)30096 $-6$.
4. Dai M, Liu D, Liu M, et al. Patients with cancer appear more vulnerable to SARS-CoV-2: a multicenter study during the COVID-19 outbreak. Cancer Discov. 2020;10(6):783-91. https ://doi.org/10.1158/2159-8290.CD-20-0422.

5. Mohindra P, Buckey CR, Chen S, Sio TT, Rong Y. Radiation therapy considerations during the COVID-19 pandemic: literature review and expert opinions. J Appl Clin Med Phys. 2020;21(5):6-12. https://doi.org/10.1002/acm2.12898.

6. Kumar D, Dey T. Treatment delays in oncology patients during COVID-19 pandemic: a perspective. J Glob Health. 2020;10(1):010367. https://doi.org/10.7189/jogh.10.010367.

7. Barton MB, Jacob S, Shafiq J, et al. Estimating the demand for radiotherapy from the evidence: a review of changes from 2003 to 2012. Radiother Oncol. 2014;112(1):140-4. https://doi. org/10.1016/j.radonc.2014.03.024.

8. Zhang D, Li T, Wang P, et al. Experts consensus on epidemic prevention and control in radiotherapy centers during the COVID-19 outbreak: Experiences from Sichuan Province. Clin Transl Radiat Oncol. 2020;24:88-91. https://doi.org/10.1016/j. ctro.2020.06.010.

9. https://www.radioterapiaitalia.it/wp-content/uploads/2020/03/v2-Documento-AIRO-COVID-19-24-03-2020.pdf. Documento di indirizzo per la valutazione e la gestione del rischio dei pazienti e degli operatori nei reparti di radioterapia oncologica in corso di diffusione del COVID-19. Accessed on July 24th, 2020.

10. COVID-19's Impact on Radiation Oncology. Initial Results of a Nationwide Physician Survey, 5/20/20. https://www.astro.org/ ASTRO/media/ASTRO/News\%20and\%20Publications/PDFs/ ASTROCOVID19Survey1-ExecSummary.pdf. Accessed on July 24th, 2020.

11. Slotman BJ, Lievens Y, Poortmans P, et al. Effect of COVID-19 pandemic on practice in European radiation oncology centers. Radiother Oncol. 2020;150:40-2. https://doi.org/10.1016/j.radon c.2020.06.007.

12. https://www.money.it/Proroga-stato-di-emergenza-31-genna io-cosa-cambia. Accessed on October 15th 2020.

13. Guckenberger M, Belka C, Bezjak A, et al. Practice recommendations for lung cancer radiotherapy during the COVID-19 Pandemic: an ESTRO-ASTRO consensus statement. Int J Radiat Oncol Biol Phys. 2020a;107(4):631-40. https://doi.org/10.1016/j. ijrobp.2020.05.012.

14. Liao Z, Rivin Del Campo E, Salem A, Pang Q, Liu H, Lopez Guerra JL. Optimizing lung cancer radiation treatment worldwide in COVID-19 outbreak. Lung Cancer. 2020;146:230-5. https:// doi.org/10.1016/j.lungcan.2020.05.029.

15. Passaro A, Addeo A, Von Garnier C, et al. ESMO Management and treatment adapted recommendations in the COVID-19 era: Lung cancer. ESMO Open. 2020;5(Suppl 3):e000820. https://doi. org/10.1136/esmoopen-2020-000820.

16. Magrini SM, Borghetti P, Filippi AR, et al. Letter to the editor regarding ESTRO-ASTRO guidelines on lung cancer radiotherapy during COVID-19 pandemic. Radiother Oncol. 2020;147:229-30. https://doi.org/10.1016/j.radonc.2020.04.034.

17. Guckenberger M, Belka C, Bezjak A, et al. Practice recommendations for lung cancer radiotherapy during the COVID-19 pandemic: an ESTRO-ASTRO consensus statement. Radiother Oncol. 2020b;146:223-9. https://doi.org/10.1016/j.radonc.2020.04.001.

18. Alterio D, Volpe S, Marvaso G, et al. Head and neck cancer radiotherapy amid COVID-19 pandemic: report from Milan, Italy. Head Neck. 2020;42(7):1482-90. https://doi.org/10.1002/ hed.26319.

19. Thomson DJ, Palma D, Guckenberger M, et al. Practice recommendations for risk-adapted head and neck cancer radiation therapy during the COVID-19 pandemic: an ASTRO-ESTRO consensus statement. Int J Radiat Oncol Biol Phys. 2020;107(4):618-27. https://doi.org/10.1016/j.jirobp.2020.04.016. 
20. De Felice F, Polimeni A, Tombolini V. The impact of Coronavirus (COVID-19) on head and neck cancer patients' care. Radiother Oncol. 2020;147:84-5. https://doi.org/10.1016/j.radon c.2020.03.020.

21. Obek C, Doganca T, Argun OB, Kural AR. Management of prostate cancer patients during COVID-19 pandemic. Prostate Cancer Prostatic Dis. 2020. https://doi.org/10.1038/s41391-020-0258-7.

22. Coles CE, Aristei C, Bliss J, et al. International guidelines on radiation therapy for breast cancer during the COVID-19 Pandemic. Clin Oncol (R Coll Radiol). 2020;32(5):279-81. https:// doi.org/10.1016/j.clon.2020.03.006.

23. de Azambuja E, Trapani D, Loibl S, et al. ESMO Management and treatment adapted recommendations in the COVID-19 era: breast cancer. ESMO Open. 2020;5(Suppl 3):e000793. https:// doi.org/10.1136/esmoopen-2020-000793.

24. Han K, Mendez L, D'Souza D, et al. Management of gynecologic cancer: choosing radiotherapy wisely by 3 Southern Ontario academic centers during the COVID-19 pandemic. Radiother Oncol. 2020;151:15-6. https://doi.org/10.1016/j.radonc.2020.07.021.

25. Siavashpour Z, Taghizadeh-Hesary F, Rakhsha A. Recommendations on management of locally advanced rectal cancer during the COVID-19 pandemic: an Iranian consensus. J Gastrointest Cancer. 2020. https://doi.org/10.1007/s12029-020-00454-4.

26. Jones CM, Radhakrishna G, Aitken K, et al. Considerations for the treatment of pancreatic cancer during the COVID-19 pandemic: the UK consensus position. Br J Cancer. 2020. https://doi. org/10.1038/s41416-020-0980-x.

27. Catanese S, Pentheroudakis G, Douillard JY, Lordick F. ESMO management and treatment adapted recommendations in the COVID-19 era: pancreatic cancer. ESMO Open. 2020;5(Suppl 3):e000804. https://doi.org/10.1136/esmoopen-2020-000804.

28. Tchelebi LT, Haustermans K, Scorsetti M, et al. Recommendations for the use of radiation therapy in managing patients with gastrointestinal malignancies in the era of COVID-19. Radiother
Oncol. 2020;148:194-200. https://doi.org/10.1016/j.radon c. 2020.04.010.

29. Vavassori A, Tagliaferri L, Vicenzi L, et al. Practical indications for management of patients candidate to Interventional and Intraoperative Radiotherapy (Brachytherapy, IORT) during COVID-19 pandemic - a document endorsed by AIRO (Italian Association of Radiotherapy and Clinical Oncology) Interventional Radiotherapy Working Group. Radiother Oncol. 2020;149:73-7. https ://doi.org/10.1016/j.radonc.2020.04.040.

30. Wang W, Hu K, Qiu J, Zhang F. Radiotherapy after the easing of public restrictions during COVID-19 epidemic. Radiat Oncol. 2020;15(1):166. https://doi.org/10.1186/s13014-020-01612-5.

31. Portaluri M, Barba MC, Musio D, Tramacere F, Pati F, Bambace S. Hypofractionation in COVID-19 radiotherapy: a mix of evidence based medicine and of opportunities. Radiother Oncol. 2020;150:191-4. https://doi.org/10.1016/j.radonc.2020.06.036.

32. Barra S, Guarnieri A, di Bastia MBME, et al. Short fractionation radiotherapy for early prostate cancer in the time of COVID-19: long-term excellent outcomes from a multicenter Italian trial suggest a larger adoption in clinical practice. Radiol Med. 2020. https ://doi.org/10.1007/s11547-020-01216-9.

33. Faivre-Finn C, Fenwick JD, Franks KN, et al. Reduced fractionation in lung cancer patients treated with curative-intent radiotherapy during the COVID-19 pandemic. Clin Oncol (R Coll Radiol). 2020;32(8):481-9. https://doi.org/10.1016/j.clon.2020.05.001.

34. Nagar H, Formenti SC. Cancer and COVID-19 - potentially deleterious effects of delaying radiotherapy. Nat Rev Clin Oncol. 2020;17(6):332-4. https://doi.org/10.1038/s41571-020-0375-1.

Publisher's Note Springer Nature remains neutral with regard to jurisdictional claims in published maps and institutional affiliations.

\section{Affiliations}

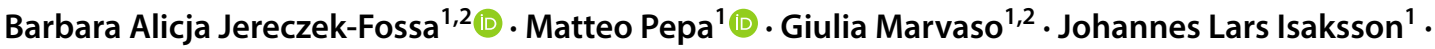
Carlo Pietro Soatti ${ }^{3}$. Luigi Franco Cazzaniga ${ }^{4}$. Giovanni Battista Ivaldi ${ }^{5}$ - Marcello Amadori ${ }^{6}$. Paolo Antognoni ${ }^{7}$. Stefano Arcangeli ${ }^{8}$. Alberto Buffoli ${ }^{9}$. Giancarlo Beltramo ${ }^{10}$. Mario Bignardi ${ }^{11}$. Stefano Bracelli ${ }^{12}$. Lorenza Bruschieri ${ }^{13}$. Simona Castiglioni ${ }^{14}$. Gianpiero Catalano ${ }^{15} \cdot$ Nadia Di Muzio $^{16} \odot$. Carlo Fallai ${ }^{17}$. Laura Fariselli $^{18}$ - Andrea Riccardo Filippi ${ }^{19}$ - Alberto Gramaglia ${ }^{20}$. Corrado Italia ${ }^{21}$. Fabrizio Lombardi ${ }^{22}$. Stefano Maria Magrini ${ }^{23} \cdot$ Simonetta $\mathrm{Nava}^{24} \cdot$ Ester Orlandi $^{25} \cdot$ Nadia Pasinetti $^{26}$. Elena Lara Sbicego ${ }^{27}$. Luciano Scandolaro $^{28}$ - Marta Scorsetti ${ }^{29,30} \cdot$ Francesco Stiglich $^{31} \cdot$ Roberto Tortini $^{32}$ - Riccardo Valdagni ${ }^{2,17}$. Vittorio Vavassori ${ }^{33}$. Sandro Tonoli ${ }^{34}$. Mauro Filippo Palazzi ${ }^{35}$ on behalf of the CODRAL (Board of Directors of Radiation Oncology Departments in Lombardy) network and of AIRO-L (Italian Association of Radiotherapy and Clinical Oncology - Lombardy)

1 Division of Radiation Oncology, IEO, European Institute of Oncology, IRCCS, Via Ripamonti, 435-20141 Milan, Italy

2 Department of Oncology and Hemato-Oncology, University of Milan, Milano, Italy

3 Radiation Oncology Centre, Ospedale Manzoni, Lecco, Italy

4 Radiation Oncology Centre, Ospedale Papa Giovanni XXIII, Bergamo, Italy

5 Radiation Oncology Centre, Istituti Clinici Scientifici Maugeri, IRCCS, Pavia, Italy
6 Radiation Oncology Centre, Ospedale C. Poma, Mantova, Italy

7 Radiation Oncology Centre, Ospedale di Circolo e Fondazione Macchi, ASST Dei Sette Laghi, Varese, Italy

8 Department of Radiation Oncology, Policlinico S. Gerardo and University of Milan "Bicocca", Milano, Italy

9 Radiation Oncology Centre, Istituto Clinico S. Anna, Brescia, Italy

10 Radiation Oncology Centre, Centro Diagnostico Italiano (CDI), Milano, Italy 
11 Radiation Oncology Centre, Fondazione Poliambulanza, Brescia, Italy

12 Radiation Oncology Centre, Ospedale, Busto Arsizio, Italy

13 Division of Radiation Oncology, Ospedale Di Treviglio, Caravaggio Di Treviglio, Treviglio, Italy

14 Radiation Oncology Centre, S. Pio X-Humanitas, Milano, Italy

15 Radiation Oncology Centre, IRCCS Ospedale Multimedica, Sesto San Giovanni/Castellanza, Italy

16 Radiation Oncology Centre, IRCCS Ospedale S. Raffaele and University Vita Salute, Milano, Italy

17 Division of Radiotherapy, Fondazione IRCCS Istituto Nazionale Dei Tumori, Milano, Italy

18 Radiotherapy Unit, Fondazione IRCCS Istituto Neurologico Carlo Besta, Milano, Italy

19 Division of Radiotherapy, Fondazione IRCCS Policlinico San Matteo and University of Pavia, Pavia, Italy

20 Radiation Oncology Centre, Policlinico, Monza, Italy

21 Radiation Oncology Centre, Istituti Ospedalieri Bergamaschi, Ponte S. Pietro-Zingonia, Italy

22 Radiotherapy Unit, IRCCS Policlinico San Donato, San Donato Milanese, Italy

23 Radiation Oncology Centre, Brescia University Radiation Oncology Department, O. Alberti Radium Institute, Spedali Civili Hospital, Brescia, Italy
24 Radiation Oncology Centre, Istituti Clinici Di Pavia E Vigevano, Vigevano, Italy

25 Radiation Oncology Centre, National Centre of Oncological Hadrontherapy, CNAO, Pavia, Italy

26 Radiation Oncology Department, Esine and University of Brescia, Esine, Italy

27 Radiation Oncology Centre, Istituto Clinico Sant'Ambrogio, Milano, Italy

28 Radiation Oncology Centre, Ospedale Sant'Anna, ASST Lariana, Como, Italy

29 Radiotherapy and Radiosurgery Department, Humanitas Clinical and Research Center - IRCCS, Rozzano, Milan, Italy

30 Department of Biomedical Sciences, Humanitas University, Pieve Emanuele, Milan, Italy

31 Radiation Oncology Centre, Ospedale Di Sondrio, Sondrio, Italy

32 Ospedale Di Casalpusterlengo, Azienda Ospedaliera Della Provincia Di Lodi, Casalpusterlengo, Italy

33 Unit of Radiotherapy, Cliniche Gavezzeni SPA, Bergamo, Italy

34 Division of Radiation Oncology and Nuclear Medicine, ASST di Cremona, Cremona, Italy

35 Radiotherapy Unit, ASST Ospedale Niguarda, Milano, Italy 